\title{
STUDI EKPERIMENTAL DAN SIMULASI PENGARUH SUDUT DOUBLE SEGMENTAL BAFFLE DAN LAJU ALIRAN MASSA FLUIDA PADA HEAT EXCHANGER TYPE SHELL $A N D$ TUBE TERHADAP PERPINDAHAN PANAS
}

\author{
Muhammad Syafi'i*, Tabah Priangkoso dan Darmanto \\ Jurusan Teknik Mesin Universitas Wahid Hasyim Semarang \\ Jl. Menoreh Tengah X/22 Sampangan Semarang 50236 \\ *Email: muhammadsi863@gmail.com
}

\begin{abstract}
Abstrak
Shell and tube heat exchanger (STHX) merupakan jenis penukar kalor yang banyak digunakan di industri. Namun, peningkatan performa penukar kalor ini perlu dilakukan dengan cermat karena alirannya yang kompleks di dalam shell. Shell-and-Tube Heat Exchanger berfungsi untuk menukar energi dalam bentuk panas antara fluida yang berbeda Temperature yang dapat terjadi melalui kontak langsung maupun tidak langsung. Fluida yang bertukar energi dapat berupa energi yang fasenya sama (cair ke cair atau gas ke gas) atau dua fluida yang berbeda fasenya. Penelitian ini mengkaji peningkatan performa dalam bentuk koefisien perpindahan panas total dan efektivitas dengan melakukan variasi sudut baffle menggunakan pendekatan eksperimen. Penukar kalor diuji pada laju aliran massa 0,5; 1; 1,5; dan $2 \mathrm{~kg} / \mathrm{s}$ dengan variasi sudut baffle $0^{\circ}, 10^{\circ}$, dan $20^{\circ}$. Pada pengujian eksperimen maupun simulasi semakin kecil sudut baffle maka semakin besar nilai efektivitasnya dan semakin besar laju aliran massa maka semakin besar pula nilai koefisien perpindahan panas totalnya. Pada pengujian simulasi nilai efektivitas dengan sudut baffle $0^{\circ}$ memiliki nilai maksimal 1,82\% dengan nilai koefisien perpindahan panas total $1607 \mathrm{~W} / \mathrm{m}^{2} . \mathrm{K}, 10^{\circ}$ memiliki nilai $1,79 \%$ dengan nilai koefisien perpindahan panas total $1581 \mathrm{~W} / \mathrm{m}^{2} . \mathrm{K}$, dan $20^{\circ}$ memiliki nilai $1,70 \%$ dengan nilai koefisien perpindahan panas total $1460 \mathrm{~W} / \mathrm{m}^{2} . \mathrm{K}$, nilai efektivitas pada pengujian eksperimen dengan sudut baffle $0^{\circ}$ memiliki nilai maksimal 1,38\% dengan nilai koefisien perpindahan panas total $741,54 \mathrm{~W} / \mathrm{m}^{2} . \mathrm{K}, 10^{\circ}$ memiliki nilai $1,29 \%$ dengan nilai koefisien perpindahan panas total $740,56 \mathrm{~W} / \mathrm{m}^{2} . \mathrm{K}$, dan $20^{\circ}$ memiliki nilai $1,14 \%$ dengan nilai koefisien perpindahan panas total $739,21 \mathrm{~W} / \mathrm{m}^{2} . K$.
\end{abstract}

Kata Kunci: Computational Fluid Dynamics, double segmental baffle, STHX, sudut baffle

\section{PENDAHULUAN}

Alat penukar kalor (heat exchanger) merupakan suatu alat yang digunakan untuk menukar energi dalam bentuk panas antara fluida yang berbeda temperatur terjadi melalui kontak langsung maupun tidak langsung. Fluida yang bertukar energi dapat berupa energi yang fasenya sama (cair ke cair atau gas ke gas) atau dua fluida yang berbeda fasenya. Alat penukar kalor sangat penting kegunaannya dalam dunia industri terhadap kelangsungan dan keberhasilan keseluruhan rangkaian proses karena dalam kegagalan alat ini yang disebabkan oleh kegagalan mekanikal atau operasional dapat menyebabkan operasi unit suatu proses. Suatu alat penukar kalor dituntut untuk memiliki kinerja yang baik agar diperoleh hasil yang maksimal serta dapat menunjang terhadap operasional unit. Salah satu karakteristik kinerja dari alat ini adalah efektivitas penukar panas.

Penukar kalor pada umumnya digunakan dalam kondisi tekanan relatif tinggi yang terdiri dari beberapa komponen seperti tabung (shell) yang di dalam disusun suatu selongsong semacam pipa dengan susunan yang rapi dengan rangkaian tertentu (tube) untuk mendapatkan luas permukaan yang optimal. Fluida dingin mengalir melalui selongsong, sedangkan fluida panas mengalir melalui tabung sehingga terjadi perpindahan panas secara konduksi dan konveksi pada bagian dinding. Aliran fluida pada shell and tube pada heat exchanger adalah parallel atau berlawanan, untuk membuat aliran pada fluida pada shell and tube pada heat exchanger menjadi cross and flow biasanya diberi penyekat atau baffle. Aliran cross flow yang didapat dengan menambahkan baffle akan membuat luas kontak fluida dengan shell pada dinding tube makin besar, sehingga perpindahan panas meningkat. Baffle juga berfungsi sebagai penjaga dan penyangga tube supaya tidak melengkung dan dapat mengurangi kemungkinan adanya vibrasi atau getaran oleh aliran fluida.

Secara teoretis baffle yang dipasang secara berdekatan akan meningkatkan perpindahan panas yang terjadi antara kedua fluida, namun hambatan yang terjadi pada fluida yang melalui celah antar baffle akan besar 
sehingga penurunan tekanan menjadi besar. Jika baffle dipasang terlalu jauh maka penurunan tekanan yang terjadi akan kecil dan menimbulkan perpindahan panas kurang baik dan timbul bahaya kerusakan pada pipa karena melengkung akibat vibrasi. Dengan pertimbangan itu maka pemasangan baffle pada heat exchanger tidak boleh terlalu dekat ataupun jauh sehingga ada jarak tertentu yang optimal untuk heat exchanger. Untuk itu maka akan dilakukan suatu penelitian untuk mempelajari pengaruh double segmental baffle terhadap aliran fluida dan perpindahan panas pada heat exchanger type shell and tube yang bertujuan untuk mengetahui karakteristik dan kinerja aliran fluida dan laju perpindahan panas pada heat exchanger yang baik serta, pressure drop yang baik dengan menggunakan program Solidworks dengan memilih permodelan k-E standard sebagai turbulence modeling serta mengaktifkan persamaan energi untuk menyimulasi aliran yang terjadi pada heat exchanger type shell and tube.

Tujuan penelitian ini adalah untuk mengetahui pengaruh variasi sudut double segmental baffle dan pengaruh laju aliran massa pada heat exchanger type shell and tube terhadap efektivitas heat exchanger.

\section{METODOLOGI}

Dalam penelitian ini dilakukan secara eksperimental dan simulasi dengan variasi double segmental baffle sebesar $0^{\circ}, 10^{\circ}, 20^{\circ}$ dengan laju aliran massa $0,5 \mathrm{~kg} / \mathrm{s}, 1 \mathrm{~kg} / \mathrm{s}, 1,5$ $\mathrm{kg} / \mathrm{s}, 2 \mathrm{~kg} / \mathrm{s}$.

Tube yang digunakan adalah tube dengan tipe shell and tube yang disusun secara melingkar, dan baffle yang digunakan adalah double segmental baffle. Model viscous yang digunakan adalah turbulensi model $\mathrm{k}-\mathcal{E}$ standar, dimana fluida yang digunakan adalah air aquades dan air water chiler dengan boundary condition dengan $\mathrm{Ph} 0 \%$. Untuk mengetahui karakter dan performa heat exchanger dilakukan dengan menggunakan permodelan software Solidworks 3D 2016.

\section{Alat}

Alat yang digunakan dalam pengujian adalah sebagai berikut:

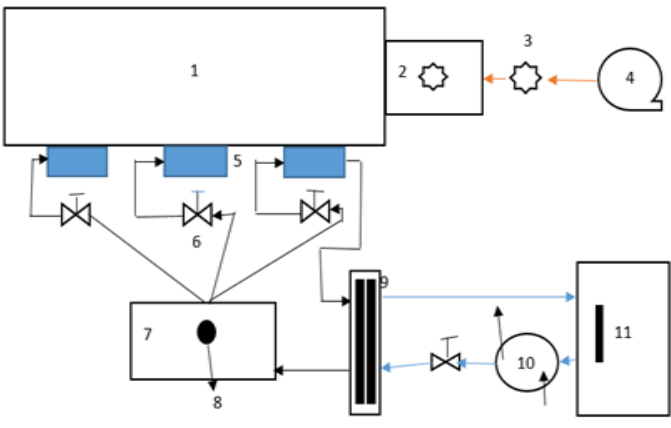

Keterangan:

1. Mesin extruder 7. Bak air akuades.

2. Gear box.

8. Thermocouple.

3. Gear couple.

9. STHX.

4. DC Motor.

5. Heater jacket.

10. Pompa.

11. Mesin chiller.

6. Ep valve.

$\longrightarrow$ : alur air akuades.

$\rightarrow$ : alur transmisi.

$\longrightarrow$ : alur air chiller.

\section{Bahan}

Bahan yang digunakan dalam pengujian adalah sebagai berikut:

1) Heat exchanger type shell and tube dengan double segmental baffle.

2) Pompa sirkulasi untuk menyuplai air akuades dari tandon.

3) Mesin water chiller untuk menyuplai fluida air dingin

4) Mesin main extruder dan heater jacket untuk media percobaan.

5) Pipa 2 inch untuk air chiller dan pipa ukuran $12 \mathrm{~mm}$ air akuades.

6) Heater jacket.

\section{Rancangan Percobaan.}

Uji eksperimen pada STHX (Shell and tube heat exchanger) dengan laju massa $0,5 \mathrm{~kg} / \mathrm{s}$, $1 \mathrm{~kg} / \mathrm{s}, 1,5 \mathrm{~kg} / \mathrm{s}$, dan $2 \mathrm{~kg} / \mathrm{s}$. Eksperimen dilakukan pada unit STHX ini di dukung oleh beberapa komponen pendukung seperti yang terlihat pada tabel 1. Baffle terbuat dari stainless steel untuk mempermudah fabrikasi dan perakitan.

Data percobaan eksperimen diperoleh dari pengambilan data laju massa, dan temperatur masuk serta keluar fluida pada STHX sebelum dilakukan beberapa perhitungan variabel seperti:

1. Koefisien perpindahan panas total.

2. Efektivitas performa heat exchanger. 
Simulasi CFD (computational fluid dynamics) bertujuan untuk mengetahui variabelvariabel tersebut (koefisien perpindahan panas total dan efektivitas performa heat exchanger) dengan metode simulasi dengan menggunakan software Solidworks 2016. Hasil dari simulasi CFD (Computational Fluid Dynamics) yang berupa full report kemudian dibandingkan dengan data eksperimen untuk mendukung karakteristik aliran STHX.

Pada simulasi yang dilakukan pada software Solidworks flow simulation 2016 ada beberapa properties yang harus di perhatikan seperti Turbulence model yang digunakan adalah modified $k-\varepsilon$ serta Meshing technique yang dipilih adalah Immerse boundary Cartesian. Turbulence parameter simulasi adalah turbulent intensity $2 \%$ dan turbulence length $0,0015 \mathrm{~m}$. Boundary Condition yang dipilih Inlet mass flow dan static pressure.

Tabel 1. Spesifikasi komponen pendukung

\begin{tabular}{|l|l|l|}
\hline No & Nama & Spesifikasi \\
\hline 1 & Unit STHX & $\begin{array}{l}\text { Dimensi }=\mathrm{P}: 62,1 \mathrm{~cm} \text { D shell: } 12,5 \mathrm{~cm} \\
\text { D baffle: } 10 \mathrm{~cm} \text { D tube: } 0,8 \mathrm{~cm} \\
\text { Jumlah tube } 48 \text { buah }\end{array}$ \\
\hline 2 & Unit mesin chiller & Merk Thermo Q dengan kapasitas $500 \mathrm{TR}$ \\
\hline 3 & Pompa air aquades & Merk Yaskawa 40 Lpm daya: $200 \mathrm{~W}$ \\
\hline 4 & Tandon air aquades & Drum D: 1 Meter \\
\hline 5 & Panel control & 1 Unit \\
\hline 6 & Flow meter & Merk Wipro tipe P10307681 (6 digit) \\
\hline 7 & Pipa koneksi & 1,5 inch \\
\hline 7 & Valve & $\begin{array}{l}\text { Ball valve } 1,5 \text { inch dan gate valve } 1 \text { inch } \\
\text { merk Kitz }\end{array}$ \\
\hline 8 & Heater & 4 Heater jacket dengan daya $2400 \mathrm{KW}$ \\
\hline 9 & Sensor temperatur & Thermocouple type $\mathrm{K}$ dengan merk autonics \\
\hline 10 & Oil preassure gauge & Merk Tekiro $500 \mathrm{Psi} 40 \mathrm{~kg} / \mathrm{cm}^{2}$ \\
\hline
\end{tabular}

Tabel 2. Tabel rancangan percobaan.

\begin{tabular}{|c|c|c|c|c|}
\hline Sudut baffle $\left.^{\circ}\right)$ & \multicolumn{4}{|c|}{ Laju aliran massa $(\mathrm{kg} / \mathrm{s})$} \\
\hline 0 & 0,5 & 1 & 1,5 & 2 \\
\hline 10 & 0,5 & 1 & 1,5 & 2 \\
\hline 20 & 0,5 & 1 & 1,5 & 2 \\
\hline
\end{tabular}

\section{HASIL DAN PEMBAHASAN}

Pada Gambar 4.1 dijelaskan mengenai alur laju fluida yakni inlet air panas sisi shell berada di A berwarna merah, sedangkan inlet air dingin sisi shell sebelah kiri berwarna biru tua berada di a, outlet air panas sisi shell berada di B dan berwarna orange, sedangkan untuk outlet air dingin sisi shell berada di $\mathrm{b}$ dan berwarna biru muda.

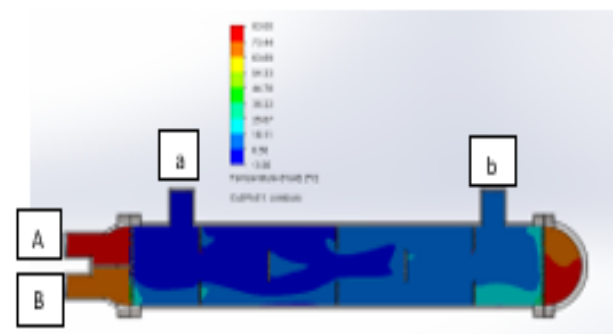

(a)

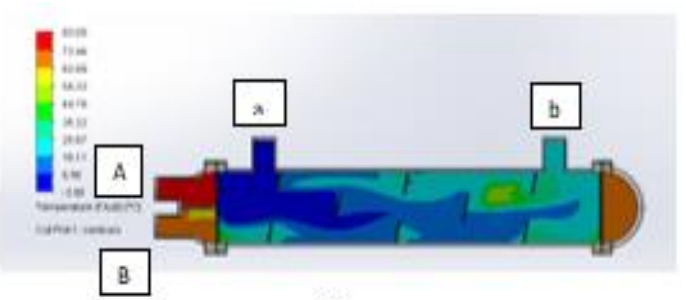

(b)

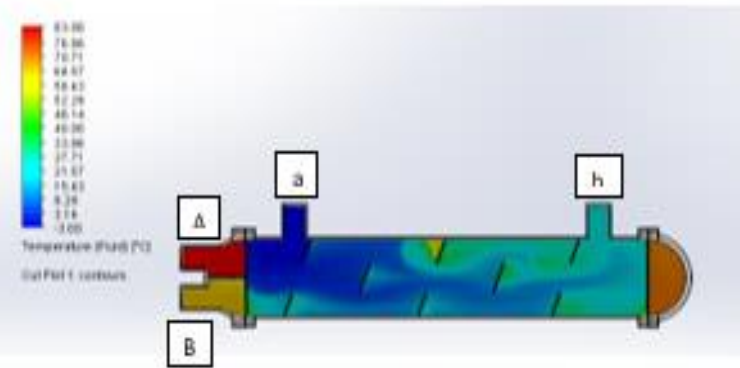

(c)

Gambar 3. Kontur temperatur baffle jarak $10 \mathrm{~cm}$. (a) sudut $0^{\circ}$ laju aliran massa $0,5 \mathrm{~kg} / \mathrm{s}$;

(b) sudut $10^{\circ}$ laju aliran massa $0,5 \mathrm{~kg} / \mathrm{s}$;

(c) sudut $20^{\circ}$ laju aliran massa $0,5 \mathrm{~kg} / \mathrm{s}$

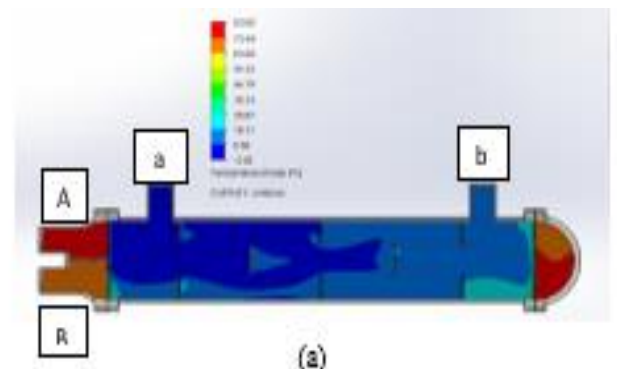

(a)

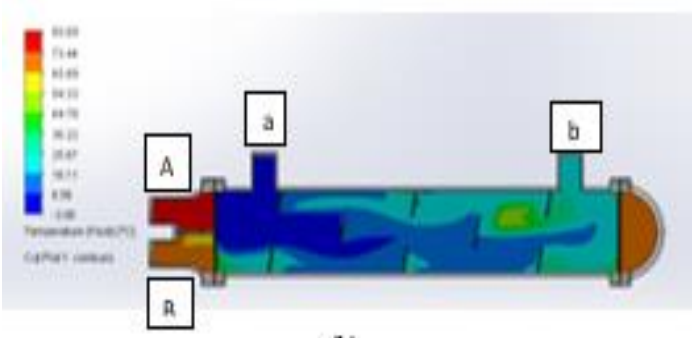

(b) 


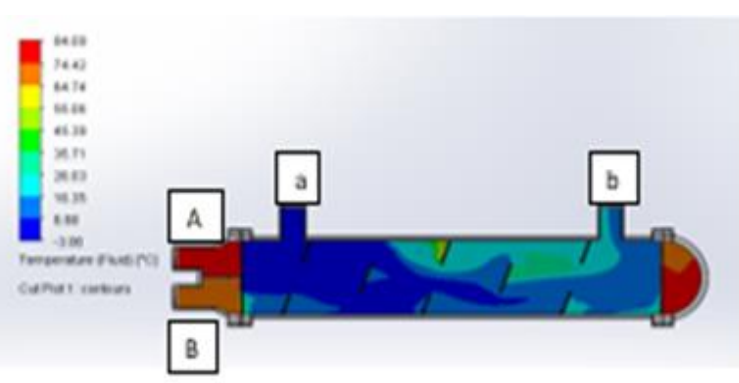

(c)

Gambar 4.2 Kontur temperatur baffle jarak $10 \mathrm{~cm}$. (a) sudut $0^{\circ}$ laju aliran massa $1 \mathrm{~kg} / \mathrm{s}$ (b) sudut $10^{\circ}$ laju aliran massa $1 \mathrm{~kg} / \mathrm{s}$, (c) sudut $20^{\circ}$ laju aliran massa $1 \mathrm{~kg} / \mathrm{s}$

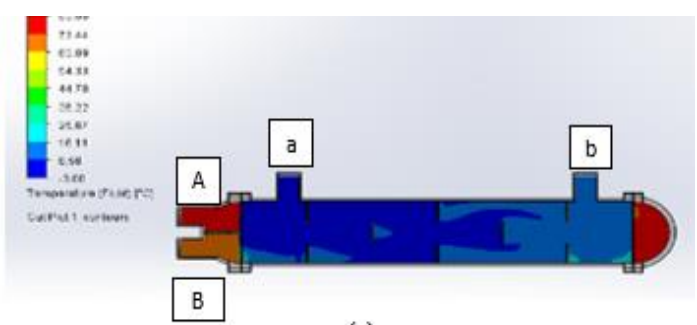

(a)

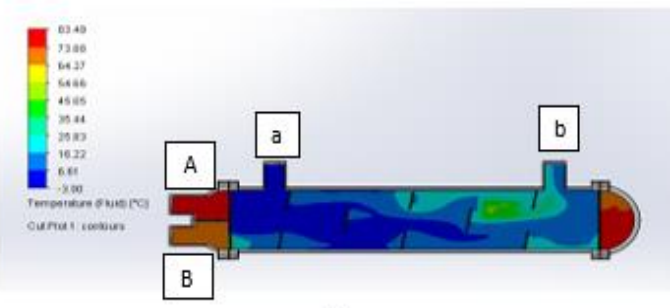

(b)

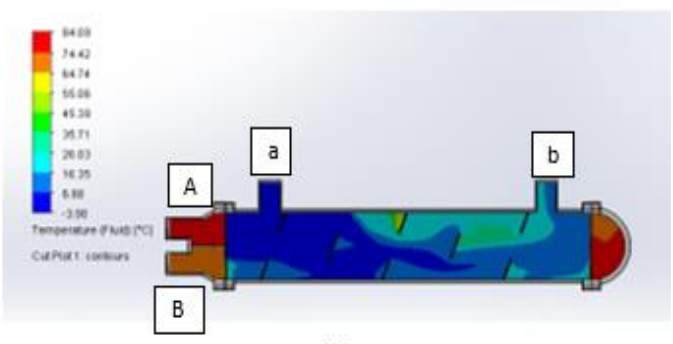

(c)

Gambar 4.3 Kontur temperatur baffle jarak $10 \mathrm{~cm}$. (a) sudut $0^{\circ}$ laju aliran massa $1,5 \mathrm{~kg} / \mathrm{s}$, (b) sudut $10^{\circ}$ laju aliran massa $1,5 \mathrm{~kg} / \mathrm{s}$, (c) sudut $20^{\circ}$ laju aliran massa $1,5 \mathrm{~kg} / \mathrm{s}$

Kontur temperatur pada tiga konfigurasi baffle ditunjukkan pada Gambar 4.1-4.4 Kontur yang ditampilkan pada saat laju massa disisi shell dan disisi tube sebesar $0,5 \mathrm{~kg} / \mathrm{s}$. Pada kontur tersebut menunjukkan aliran fluida disisi shell mengalami turbulensi aliran lebih besar karena struktur pada sudut baffle $0^{\circ}$, sementara pada konfigurasi sudut $10^{\circ}$ aliran fluida di shell langsung menuju ke bawah dengan turbulensi yang tidak besar. Hal ini yang mengakibatkan nilai perpindahan panas pada konfigurasi sudut baffle $0^{\circ}$ relatif lebih besar dibandingkan dengan konfigurasi sudut baffle $10^{\circ}$.

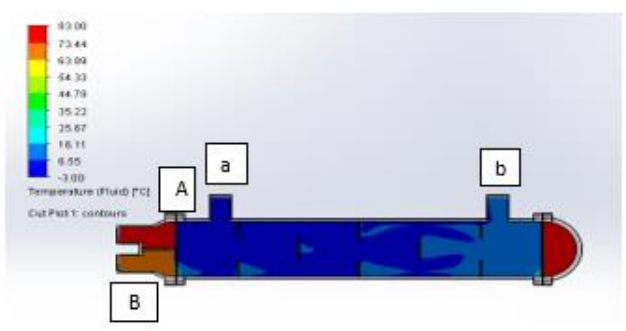

(a)

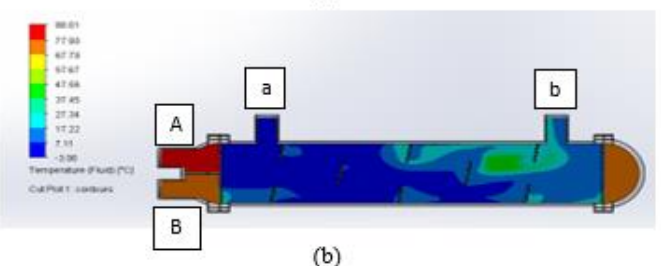

(b)

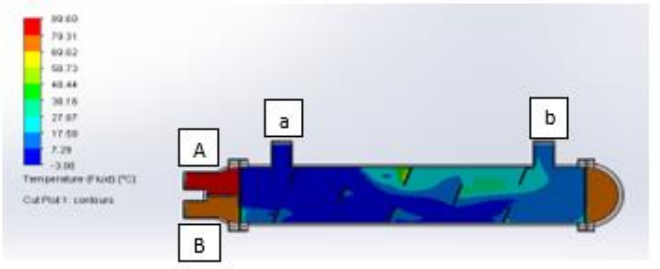

(c)

Gambar 4.4 Kontur temperatur baffle jarak $10 \mathrm{~cm}$ (a) sudut $0^{\circ}$ laju aliran massa $2 \mathrm{~kg} / \mathrm{s}$, (b) sudut $10^{\circ}$ laju aliran massa $2 \mathrm{~kg} / \mathrm{s}$, (c) sudut $20^{\circ}$ laju aliran massa $2 \mathrm{~kg} / \mathrm{s}$

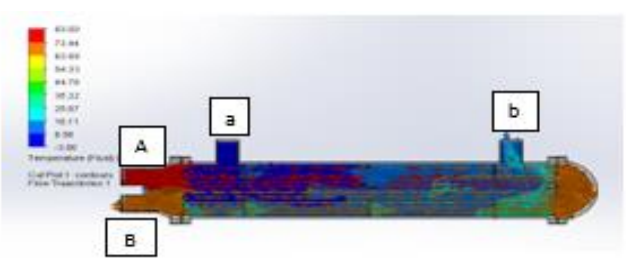

(a)

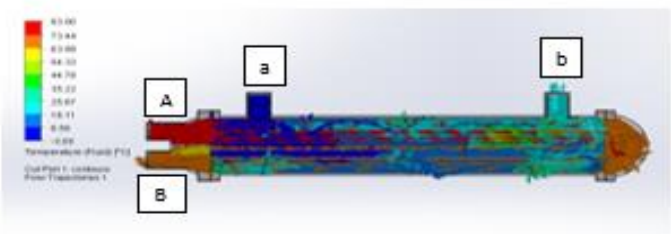

(b)

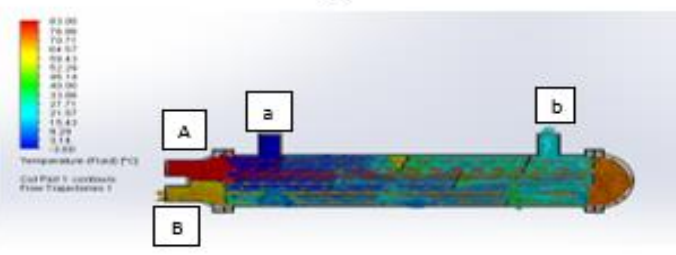

(c)

Gambar 4.5 Kontur kecepatan dan streamline baffle 10 jarak cm

(a) sudut $0^{\circ}$ laju aliran massa $0,5 \mathrm{~kg} / \mathrm{s}$,

(b) sudut $10^{\circ}$ laju aliran massa $0,5 \mathrm{~kg} / \mathrm{s}$

(c) sudut $20^{\circ}$ laju aliran massa $0,5 \mathrm{~kg} / \mathrm{s}$ 
Pada Gambar 4.5-4.8 menunjukkan kecepatan dan streamline pada variasi sudut baffle $0^{\circ}, 10^{\circ}, 20^{\circ}$ dengan variasi laju aliran massa antara $0,5 \mathrm{~kg} / \mathrm{s}, 1 \mathrm{~kg} / \mathrm{s}, 1,5 \mathrm{~kg} / \mathrm{s}$, dan 2 $\mathrm{kg} / \mathrm{s}$. Gambar 4.5-4.8 menunjukkan aliran mengalami percepatan setelah melewati segmen baffle dengan beberapa zona resirkulasi terdapat di sekitar aliran primer.

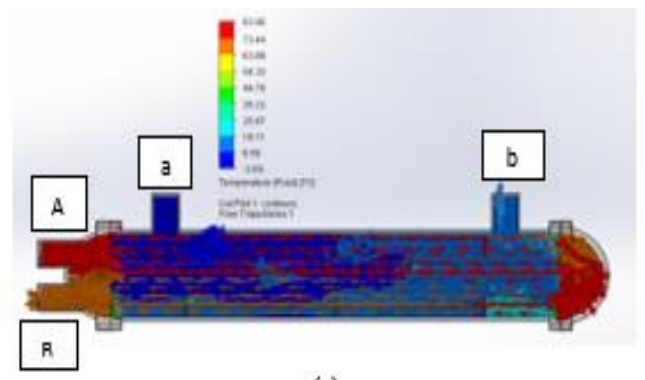

(a)

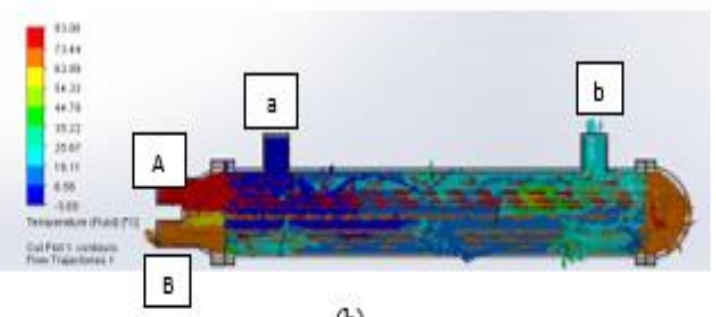

(b)

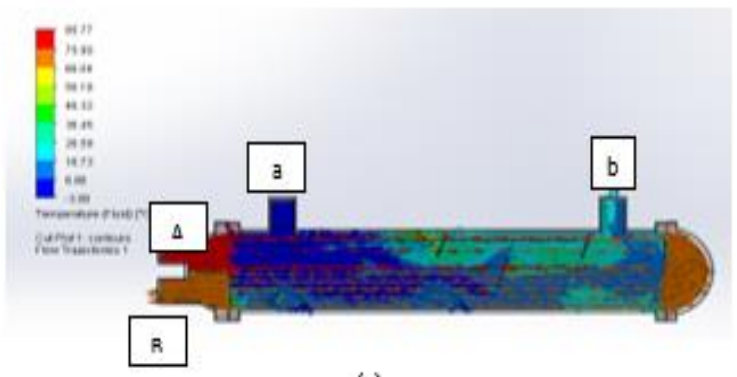

(c)

Gambar 4.6 Hasil simulasi Kontur kecepatan dan streamline baffle jarak $10 \mathrm{~cm}$

(a) sudut $0^{\circ}$ laju aliran massa $1 \mathrm{~kg} / \mathrm{s}$,

(b) sudut $10^{\circ}$ laju aliran massa $1 \mathrm{~kg} / \mathrm{s}$

(c) sudut $20^{\circ}$ laju aliran massa $1 \mathrm{~kg} / \mathrm{s}$.

Aliran primer yang memberi kontribusi besar dalam koefisien perpindahan panas terlihat lebih jelas pada konfigurasi sudut baffle $0^{\circ}$ terlihat dari pada aliran primer pada konfigurasi sudut baffle $20^{\circ}$. Aliran primer ditandai dengan kontur kecepatan yang lebih tinggi dibandingkan dengan aliran di sekelilingnya dimana terdapat zona resirkulasi. Zona resirkulasi terlihat dari timbul aliran balik (backflow) dan vortex yang dapat menghambat. Zona resirkulasi berkurang seiring dengan yang berpengaruh terhadap peningkatan kenaikan kecepatan aliran. Hal ini dapat mengakibatkan kenaikan perpindahan panas. Zona resirkulasi pada konfigurasi sudut baffle $0^{\circ}$ lebih banyak ditemukan dibandingkan zona resirkulasi pada konfigurasi $20^{\circ}$ baffle. Hal ini yang menyebabkan proses perpindahan panas pada sudut baffle $20^{\circ}$ segmental lebih baik.

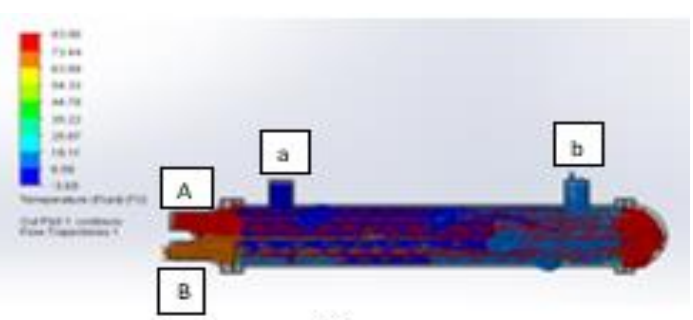

(a)

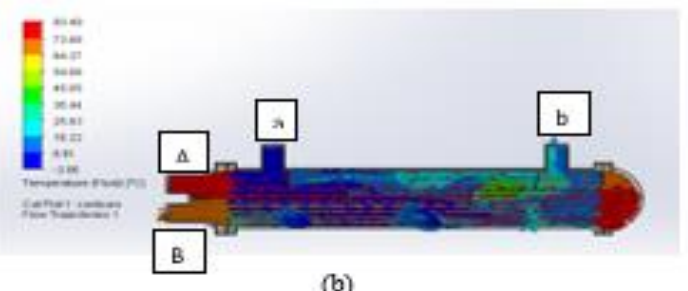

(b)

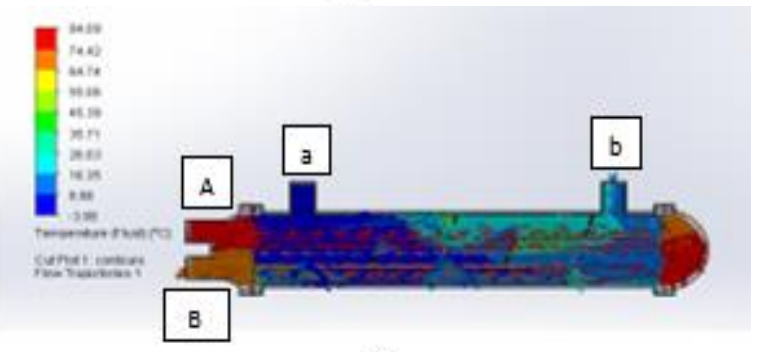

(c)

Gambar 4.7 Hasil simulasi Kontur kecepatan dan streamline baffle jarak $10 \mathrm{~cm}$.

(a) sudut $0^{\circ}$ laju aliran massa $1,5 \mathrm{~kg} / \mathrm{s}$,

(b) sudut $10^{\circ}$ laju aliran massa $1,5 \mathrm{~kg} / \mathrm{s}$

(c) sudut $20^{\circ}$ laju aliran massa $1,5 \mathrm{~kg} / \mathrm{s}$

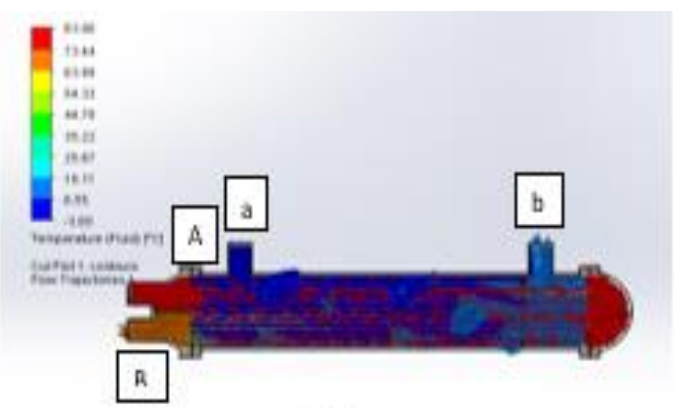

(a)

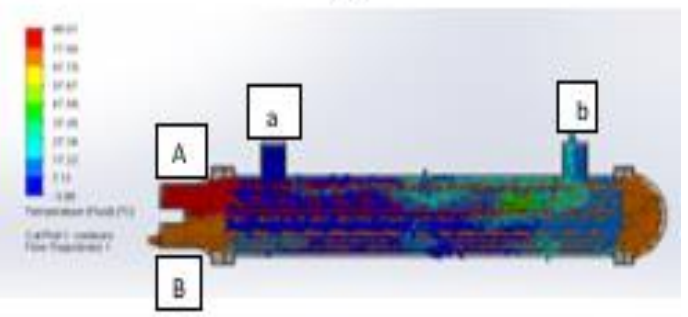

(b) 


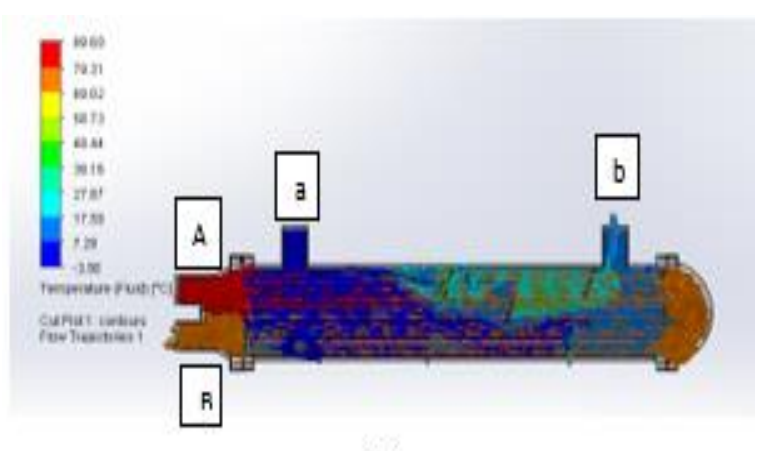

(c)

Gambar 4.8 Hasil simulasi Kontur kecepatan dan streamline baffle jarak $10 \mathrm{~cm}$.

(a) sudut $0^{\circ}$ laju aliran massa $2 \mathrm{~kg} / \mathrm{s}$,

(b) sudut $10^{\circ}$ laju aliran massa $2 \mathrm{~kg} / \mathrm{s}$

(c) sudut $20^{\circ}$ laju aliran massa $2 \mathrm{~kg} / \mathrm{s}$

Kontur streamline pada pengujian simulasi menunjukkan bahwa aliran yang terjadi pada fluida di dalam STHX adalah aliran turbulent dengan rata-rata turbulent length hingga 0,004-0,007 $\mathrm{m}$ dengan progres $100 \%$ dan turbulent intensity dengan rata-rata $0,26 \mathrm{~m}$ dengan progres $100 \%$ dengan nilai efektivitas antara $1,45 \%-1,82 \%$ baik pada STHX dengan variasi sudut baffle $0^{\circ}, 10^{\circ}$, dan $20^{\circ}$ dengan variasi laju aliran massa $0,5 \mathrm{~kg} / \mathrm{s}$ hingga $2 \mathrm{~kg} / \mathrm{s}$.

\section{Variasi Laju Aliran Massa}

Hasil penelitian dengan variasi sudut baffle ditampilkan dengan dua variabel pendukung yaitu koefisien perpindahan panas total dan efektivitas yang masing-masing terhadap fungsi laju massa.

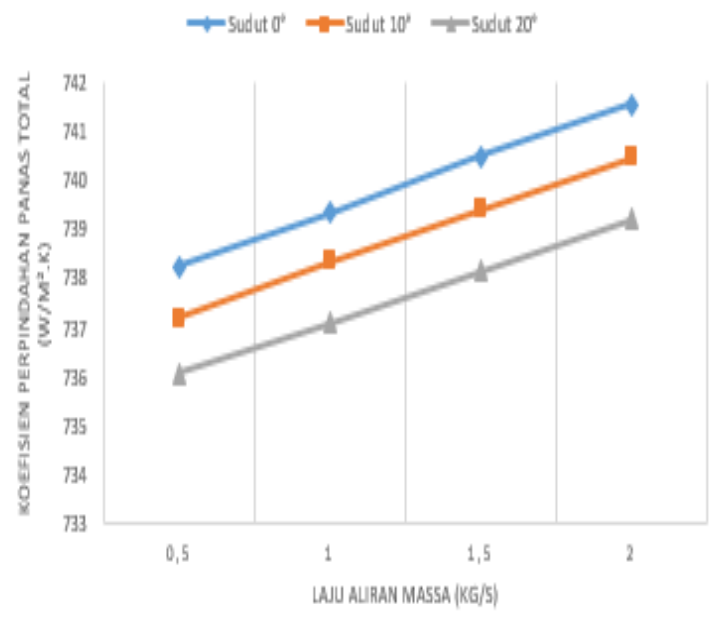

Gambar 4.9 Hubungan koefisien perpindahan panas total terhadap laju aliran massa

Hubungan koefisien perpindahan panas total terhadap laju massa ditunjukkan pada
Gambar 4.9 Kedua grafik memiliki trend yang sama yaitu koefisien perpindahan panas total semakin meningkat seiring dengan peningkatan laju massa baik pada sudut $0^{\circ}, 10^{\circ}$, maupun $20^{\circ}$. Pada sudut baffle $20^{\circ}$, nilai koefisien perpindahan panas total relatif lebih tinggi jika dibandingkan saat menggunakan sudut baffle $0^{\circ}$ baik dalam pengujian nyata maupun pengujian simulasi.

Sedangkan nilai koefisien perpindahan panas total terendah saat menggunakan baffle $20^{\circ}$ pada eksperimen adalah $736,05 \mathrm{~W} / \mathrm{m}^{2} . \mathrm{K}$ dengan variasi laju aliran masa $0,5 \mathrm{Kg} / \mathrm{s}$ dengan nilai efektivitas $0,97 \%$, sedangkan nilai tertinggi sebesar adalah $739,21 \mathrm{~W} / \mathrm{m}^{2} . \mathrm{K}$ dengan variasi laju aliran masa $2 \mathrm{~kg} / \mathrm{s}$ dengan nilai efektivitas $1,14 \%$. Pada pengujian simulasi nilai koefisien perpindahan panas total terendah adalah 1102 $\mathrm{W} / \mathrm{m}^{2} . \mathrm{K}$ dengan variasi laju aliran masa $0,5 \mathrm{~kg} / \mathrm{s}$ dengan nilai efektivitas sebesar $1,45 \%$, sedangkan nilai tertinggi sebesar $1460 \mathrm{~W} / \mathrm{m}^{2} . \mathrm{K}$ dengan variasi laju aliran masa $2 \mathrm{~kg} / \mathrm{s}$ dengan nilai efektivitas $1,70 \%$ atau mengalami kenaikan sebesar $12 \%$ pada nilai koefisien perpindahan panas totalnya. Pada pengujian eksperimen dengan laju aliran massa $1,5 \mathrm{~kg} / \mathrm{s}$ nilai efektivitas tertinggi terjadi pada sudut $0^{\circ}$ dengan nilai $1,31 \%$ dengan nilai koefisien perpindahan panas total adalah $740,48 \mathrm{~W} / \mathrm{m}^{2} . \mathrm{K}$, sedangkan pada pengujian simulasi dengan aliran massa yang sama yakni $1,5 \mathrm{~kg} / \mathrm{s}$ memiliki nilai efektivitas tertinggi pada sudut $0^{\circ}$ dengan nilai efektivitas $1,73 \%$ dengan nilai koefisien perpindahan panas total sebesar $1599 \mathrm{~W} / \mathrm{m}^{2} . \mathrm{K}$.

Sedangkan pada saat heat exchanger dengan sudut baffle $0^{\circ}$ koefisien perpindahan panas total pada pengujian eksperimen terendah adalah $738,24 \mathrm{~W} / \mathrm{m}^{2}$.K dengan variasi laju aliran masa $0,5 \mathrm{Kg} / \mathrm{s}$ dengan nilai efektivitas $1,18 \%$ mengalami kenaikan sebesar $5 \%$ pada nilai koefisien perpindahan panas total dari 738,24 $\mathrm{W} / \mathrm{m}^{2} . \mathrm{K}$ ke $741,54 \mathrm{~W} / \mathrm{m}^{2} . \mathrm{K}$ dengan nilai efektivitas $1,38 \%$. Sedangkan pada pengujian simulasi nilai koefisien perpindahan panas total pada sudut $0^{\circ}$ yang terendah adalah 1398 $\mathrm{W} / \mathrm{m}^{2} \mathrm{~K}$ pada variasi laju aliran masa $0,5 \mathrm{~kg} / \mathrm{s}$ dengan nilai efektivitas $1,51 \%$, sedangkan nilai tertinggi adalah $1607 \mathrm{~W} / \mathrm{m}^{2} . \mathrm{K}$ pada laju aliran masa $2 \mathrm{Kg} / \mathrm{s}$ dengan nilai efektivitas $1,82 \%$.

Pada saat heat exchanger dengan sudut baffle $10^{\circ}$ koefisien perpindahan panas total pada pengujian eksperimen terendah adalah 737,20 $\mathrm{W} / \mathrm{m}^{2} . \mathrm{K}$ dengan variasi laju aliran masa $0,5 \mathrm{Kg} / \mathrm{s}$ dengan nilai efektivitas $1,14 \%$ mengalami kenaikan sebesar $17 \%$ pada nilai koefisien 
perpindahan panas total dari $737,20 \mathrm{~W} / \mathrm{m}^{2} . \mathrm{K}$ ke $740,46 \mathrm{~W} / \mathrm{m}^{2} . \mathrm{K}$ dengan nilai efektivitas $1,22 \%$. Sedangkan pada pengujian simulasi nilai koefisien perpindahan panas total pada sudut $10^{\circ}$ yang terendah adalah $1137 \mathrm{~W} / \mathrm{m}^{2} . \mathrm{K}$ pada variasi laju aliran masa $0,5 \mathrm{~kg} / \mathrm{s}$ dengan nilai efektivitas $1,56 \%$, sedangkan nilai tertinggi adalah 1581 $\mathrm{W} / \mathrm{m}^{2} . \mathrm{K}$ pada laju aliran masa $2 \mathrm{~kg} / \mathrm{s}$ dengan nilai efektivitas $1,79 \%$.
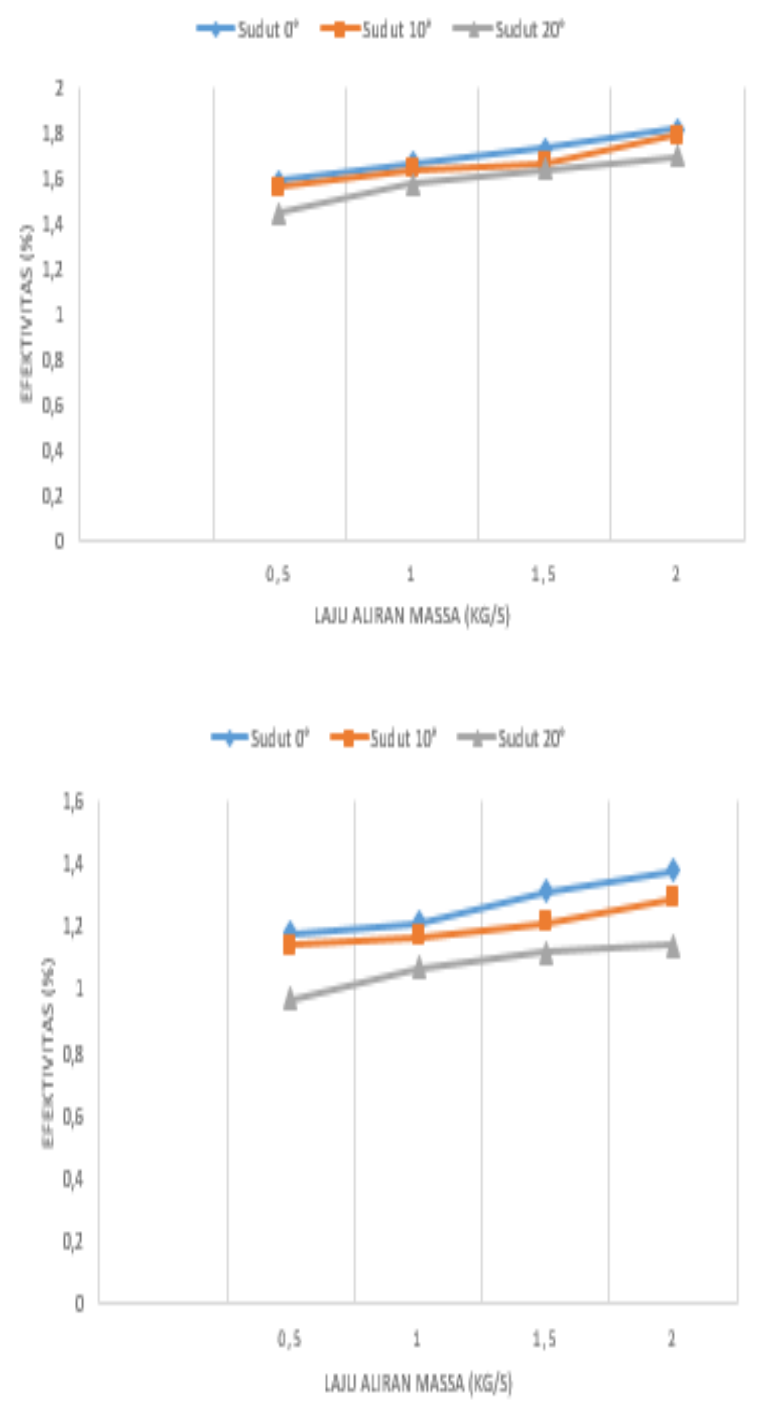

Gambar 4.10 Grafik hubungan antara efektivitas dengan laju aliran massa pada pengujian simulasi dan eksperimen.

Gambar 4.10 menunjukkan bahwa efektivitas STHX mengalami kenaikan saat terjadi kenaikan laju massa disisi shell maupun disisi tube. Efektivitas heat exchanger sudut $0^{\circ}$ lebih baik jika dibandingkan dengan efektivitas heat exchanger dengan sudut $10^{\circ}$ maupun $20^{\circ}$. Penurunan efektivitas STHX diakibatkan oleh heat transfer area yang rendah sehingga perpindahan panas rendah. Perpindahan panas yang baik ditandai dengan penurunan temperatur yang besar.

\section{Variasi Sudut Baffle}

Gambar 4.3 menunjukkan bahwa semakin kecil sudut baffle maka semakin besar pula nilai efektivitasnya. Nilai efektivitas dengan sudut baffle $0^{\circ}$ pada saat pengujian eksperimen memiliki nilai maksimal $1,29 \%, 10^{\circ}$ memiliki nilai $1,22 \%$, dan $20^{\circ}$ memiliki nilai $1,14 \%$. Nilai efektivitas menurun seiring dengan bertambahnya nilai variasi sudut dan nilai efektivitas naik ketika berkurangnya variasi pada sudut baffle. Nilai efektivitas naik seiring dengan kenaikan laju massa. Selisih terbesar terjadi saat laju massa minimal $1,5 \mathrm{~kg} / \mathrm{s}$, setelah itu selisih efektivitas mengecil seiring dengan kenaikan laju massa disisi shell dan disisi tube.

\section{Performa STHX Manual Book, Eksperimen dan Simulasi}

Berikut adalah tabel spesifik dan kapasitas STHX pada manual book:

Tabel 3. spesifikasi STHX manual book

\begin{tabular}{lll}
\hline \multicolumn{1}{c}{ Manufactured } & \multicolumn{2}{c}{$\begin{array}{c}\text { Alfa Lafal K. K, } \\
\text { LUND, SWEDEN }\end{array}$} \\
\hline Type & T5 MFG & \\
Serial No. & $30113-70645$ \\
Year & 1991 & \\
Fluid group & - & \\
Inlet - Outlet & $\mathrm{S} 1-\mathrm{S} 2$ & $\mathrm{~S} 3-\mathrm{S} 4$ \\
Volume & $4 \mathrm{~L}$ & $4 \mathrm{~L}$ \\
Design press $(P S)$ & $5,0 \mathrm{Barg}$ & 5,0 \\
Design temp $(T S)$ & $150^{\circ} \mathrm{C}$ & $\mathrm{Barg}$ \\
Test press $(P T)$ & $6,5 \mathrm{Bar}$ & $6,5 \mathrm{Bar}$ \\
Max op. temperature & $2000^{\circ} \mathrm{C}$ & \\
Test pressure date & \multicolumn{2}{c}{-} \\
\hline
\end{tabular}

Berdasarkan data di atas maka dapat dibandingkan antara data pada manual book (desain) dengan percobaan eksperimen dan simulasi terhadap kinerjanya dengan hasil sebagai berikut:

1. Pada pengujian eksperimen dan simulasi semakin kecil variasi sudut baffle dan semakin besar nilai laju aliran massa maka nilai koefisien perpindahan panas total dan efektivitas lebih baik sehingga kinerja STHX lebih baik pula, hal itu ditandai dengan nilai koefisien perpindahan panas total terbesar pada 
pengujian eksperimen dengan variasi sudut baffle $0^{\circ}$ dengan variasi laju aliran massa $2 \mathrm{~kg} / \mathrm{s}$ dengan nilai 741,54 $\mathrm{W} / \mathrm{m}^{2} . \mathrm{K}$ dengan nilai efektivitas 1,38 , sedangkan pada pengujian simulasi nilai koefisien perpindahan panas total dan efektivitas terbesar pada variasi sudut baffle dan laju aliran massa yakni sudut $0^{\circ}$ dan $2 \mathrm{~kg} / \mathrm{s}$ dengan nilai $1607 \mathrm{~W} / \mathrm{m}^{2} . \mathrm{K}$ maka dengan mengacu pada data desain nilai tersebut hampir mendekati nilai capacity range dan grade of efectivity.

2. Nilai koefisien perpindahan panas total dan efektivitas STHX pada pengujian simulasi mendekati nilai desain, karena pada pengujian simulasi semua properties pada STHX dianggap baru maka dalam pengujian simulasi data yang disajikan akurat sehingga sangat baik untuk rekomendasi dalam merancang STHX, sedangkan pada pengujian eksperimen sangat jauh, hal itu dikarenakan beberapa faktor seperti usia STHX dan faktor kerusakan elektrikal yang berupa sensor temperature dan kerusakan mekanisme seperti pressure drop yang disebabkan oleh tersumbatnya aliran fluida akibat kotoran berupa kerak.

\section{KESIMPULAN}

1. Pada pengujian eksperimen maupun simulasi pada STHX semakin kecil variasi sudut baffle maka semakin baik kinerjanya, terbukti pada variasi sudut baffle $0^{\circ}$ kinerja STHX lebih baik dibandingkan dengan STHX dengan variasi sudut baffle $10^{\circ}$ dan $20^{\circ}$, kinerja STHX yang baik ditandai dengan besarnya nilai koefisien perpindahan panas total dan efektivitasnya.

2. Pada pengujian eksperimen maupun simulasi pada STHX semakin besar laju aliran massa maka semakin besar nilai efektivitasnya. Nilai efektivitas pada pengujian eksperimen dengan variasi laju aliran massa $2 \mathrm{~kg} / \mathrm{s}$ pada sudut baffle $0^{\circ}$ memiliki nilai maksimal $1,23 \%, 10^{\circ}$ memiliki nilai $1,14 \%$, dan $20^{\circ}$ memiliki nilai $0,97 \%$, sedangkan pada pengujian simulasi nilai efektivitas dengan sudut baffle $0^{\circ}$ memiliki nilai maksimal $1,82 \%, 10^{\circ}$ memiliki nilai $1,79 \%$, dan $20^{\circ}$ memiliki nilai $1,70 \%$.

\section{DAFTAR PUSTAKA}

Akhtari. M., Haghshenasfard. M., M. R. Talaie, 2013 "Numerical and Experimentl Investigation of Heat Transfer $\bar{\alpha}-\mathrm{Al}_{2} \mathrm{O}_{3} /$ Water Nano Fluid In Double Pipe and Shell and Tube Heat Exchanger". Taylor and Francis Group, LLC.

Ardhiyangga, N., Ariwibowo, T. H., Permatasari, P.D., 2016. "Numerical Study of Shell-And-Tube Heat Exchanger Characteristics in Laminar Flow with Single Segmental Baffle”. Prosiding Seminar Nasional Teknik Kimia“., C51C57

Angga Reza. A dan Djatmiko. I., 2013. "Simulasi Performa Heat Exchanger Type Shell and Tube Dengan Double Segmental Baffle Terhadap Helical Baffle" Jurnal Teknik POMITS Vol. 2, No. 3, (2013) ISSN: 2337-3539 (2301-9271 Print).

Bell, K.J., Delaware method for shell side design, In: S. Kakac, A.E. Bergles, F. Mayinger, 1981, "Eds. Heat ExchangersThermal-Hydraulic Fundamentals and Design". Taylor \& Francis, Washington, 343-375.

Bell, K.J., Delaware method of shell side design, in: S. Kakac, A.E. Bergles, F. Mayinger (Eds.) 1986. "Heat Exchanger Sourcebook". Hemisphere, New York, 159-200.

Bell, K.J., Delaware method of shell-side design, in: R.K. Shah, E.C. Sunnarao, R.A. Mashelkar (Eds.), 1988. "Heat Transfer Equipment Design", Taylor \& Francis, New York, 145-166.

Bell, K.J., 2004. "Heat exchanger design for the process industries". ASME J. Heat Transfer 126, 877-885

B. R., Young D. F., Okiishi T. H., 2003. "Mekanika Fluida". Terjemah Dr. Ir. Harinaldi., Budiarso, M. Eng. Erlangga, Jakarta.

Crosbie, A. L., 1968 "Transient Heating or Cooling of a Plate by Combined Covection and Radiation"., Int. J. Heat and Mass Transfer., Vol. 11. Hal 305-317.

Fox., Robert W., Mc. Donald., Alan. T., 1995. "Introducion to Fluid Mechanics 4th Edition". USA: John wiley and Sons, Inc).

Indri Yaningsih., Tri Istanto., Wibawa Endra Juwana., 2015. "Studi Eksperimental Peningkatan Perpindahan Panas Aliran Turbulen Pada Alat Penukar Kalor Pipa Konsentrik Dengan Perforated Twisted 
Insert with Parralel Wings". Jurnal Teknik

Mesin Universitas Sebelas Maret Surakarta Vol. 17, No. 3 Tahun 2015: 120129.

Incopera. F. P., 1996. "Fundamentals of Head and Mass Transfer". John Willey and Soons, New York, USA.

J. P. Holman., 1997. "Perpindahan Kalor". Erlangga, Jakarta.

Kane dan Sternheim. 1991 "Fisika" (Terjemah). Bandung: AIDAB.

Master, B.I., Chunangad, K.S., Pushpanathan, V. 2003, "Fouling mitigation using helixchanger heat exchangers, Proceedings of the ECI Conference on Heat Exchanger Fouling and Cleaning". Fundamentals and Applications, 317-322.

Munson B. R., Young D. F., Okiishi T. H., 2003. "Mekanika Fluida". Terjemah Dr. Ir. Harinaldi., Budiarso, M. Eng. Erlangga, Jakarta.

Nurlan Affandi, 2018. "Simulasi Performasi Heat Exchanger Type Shell and Tube Dengan Helical Baffle dan Disk and Doughnut Baffle". Jurnal Teknik Mesin Universitas Negeri Semarang Vol. 6, No. 1, Tahun 2018: 61-68.

Serth, R. W.,2007. "Process Heat Transfer Principles and Applications". Academic Press, Oxford.

Sitompul. T. M., 1993. "Alat Penukar Kalor (Heat Exchanger)". PT. Raja Grafindo, Jakarta.

Soljic dkk., 2009. "Vibration Analysis of Heat Exchangers of Nitric Acid Plant". Chem. Biochem. Eng. Q. 23, 287-294.

Teguh Hady. A., Primadevi Permatasari., Novan Atdiyangga., Sugit Triyono., 2016. "Studi Eksperimen Karakteristik Shell and Tube Heat Exchanger Dengan Variasi Jenis Baffle dan Jarak Antar Baffle". Jurnal Ilmu Fisika Politeknik Elektronika Negeri Serabaya. Vol. 8, No. 2, (2016) ISSN: 1979-4657.

Triyono, S., Ariwibowo, T. H., Permatasari, P.D., 2016. "Numerical Study of ShellAnd-Tube Heat Exchanger Performance with Various Baffle Spacing”. Prosiding Seminar Nasional Teknik Kimia "Kejuangan", C41-C47.

Versteg, H. K., W. Malalasekera., 1995 "Computational Fluid Dynamics". Long Man Group. Ltd., USA. 